\title{
Online Design Critiques Encourage Student Interaction in the Virtual Classroom
}

\author{
Megan O. Conrad (1) \\ Department of Mechanical Engineering, University of Detroit Mercy, $4001 \mathrm{~W}$ McNichols Rd, Detroit, MI 48221, USA
}

(Received 25 June 2020; accepted 1 September 2020; published online 15 September 2020)

\section{CHALLENGE STATEMENT}

Active learning is a means of promoting student engagement while improving outcomes in STEM disciplines. $^{5}$ A factor influencing the success of active learning in the classroom is student "buy in" driven not only by student exposure to classroom activities but also solidified by the student's belief and commitment to the learning environment. ${ }^{3}$ Certainly, motivation and ease of social interaction are two elements contributing to student buy in; yet, these factors are specifically identified as two barriers associated with successful online learning. ${ }^{6}$ Thus, when COVID-19 required rapid implementation of distance learning, a challenge existed in creating a virtual, social environment where students were motivated to actively participate in classroom activities.

The "ability to apply engineering design to produce solutions that meet specific needs" is one student outcome in engineering education ${ }^{1}$ effectively accomplished, in part, through active processes like design reviews. Ultimately, aptitude in engineering design is tested in capstone courses; however, the necessary skill development is nurtured in earlier courses through opportunities to assess designs efficacy within the discipline. In a face-to-face classroom proficiency is practiced through design critiques appraising the students' own work or by critique of existing design examples identified by the student or instructor. The practice of design critique serves students in future engineering careers where design reviews provide a means of assessing and testing product efficacy. ${ }^{4}$ Therefore, a need exists to overcome challenges of

Address correspondence to Megan O. Conrad, Department of Mechanical Engineering, University of Detroit Mercy, 4001 W McNichols Rd, Detroit, MI 48221, USA. Electronic mail: conradmo@udmercy.edu active student engagement in activities like design reviews that, when successfully implemented, reinforce learning objectives and lead to student success.

\section{NOVEL INITIATIVE}

The Occupational Biomechanics course at the University of Detroit Mercy includes a series of modules focused on safe and effective design to minimize human risk of injury at work. Each module incorporates human anatomical/physiological structures and corresponding limitations, the proper design guidelines to minimize human risk, and appropriate assessment tools for evaluating a new or existing tool/job. Throughout the course, students develop their design critiquing skills through active engagement and the discussion of specific designs. With the move to online instruction, a key assignment that developed students' design critiquing skills was altered from keeping a design journal to inclass, synchronous, design critiques. To promote student comfort and engagement with the assignment, two key elements were central: (1) student selection of product/process to assess, and (2) a simple, common template for students to use as a baseline for his or her assessment. In this section, the on campus course and design critique is described followed by the changes made to accommodate online learning.

Pre-COVID19, a course assignment was to keep a "design journal" with pictures and descriptions of exemplary or questionable products or work designs encountered in internships, on campus or in other public spaces. The purpose of the design journal was to train students to notice, critique and challenge designs they encounter in everyday life. Instructions stated students should provide a picture and detailed description of each design, explain why the design was 
exemplary/questionable, and suggest design improvements. It was stressed that even exemplary designs have room for improvement. Students determined design quality (exemplary/questionable) based upon course instruction regarding proper design considerations for anthropometry and work-related biomechanics. All critiques and suggested improvements were to be based in a mathematical approach (for example, a computation of the percent of a population accommodated based on proper measurements accessed from anthropometric databases, a calculation of muscle force required for a given tool grip posture or a work assessment based on NIOSH lifting guidelines ${ }^{9}$ ). At the end of the semester each student was responsible for a journal with at least seven entries. Journals were graded using a rubric incorporating grammar/formatting, design description detail, assessment technique, and proposed improvements.

After observing decreased class participation when COVID-19 shifted courses online, the design journal assignment was modified to a format aimed to foster class discussion. Instead of seven journal entries each student was required to complete three in-class design critiques. Consistent with the journal entries, students were instructed to relate the critiques to the biomechanics knowledge gained in the course and to think of potential improvements for even exemplary designs. Three designated "Design Critique" synchronous class sessions were identified in the class schedule and all students presented on each of the three designated dates. Instructions for the three Design Critiques were consistent; however, each iteration of the design critique focused on a specific topic pertinent to the course. The topics of the successive design critiques examined (1) Design for Anthropometry, (2) Biomechanics and Posture, (3) Hand Tool Design.

The assignment remained an exercise to identify, describe, critique and improve a design from everyday life. During COVID-19 limited mobility due to social distancing affected students' design observations in public space. Students were encouraged to identify designs they encountered previously at work, through a hobby, related to tools or appliances in the house, or even examples sourced from the internet. A PowerPoint template was provided to guide the student's review. (Figure 1 depicts the instructions and template provided for the assignment.) The student completed the template with the following information: student name, a picture of the design, why the design was deemed exemplary/questionable, and suggested improvements. Design critique templates were then submitted to the instructor one day prior to an "in class" discussion. During the "in class" design critique, each student's design slide was shared in the virtual classroom one at a time. An individual student spent up to two minutes describing the chosen de- sign, explaining how the design related to the class subject matter, commenting on the design's efficacy and suggesting improvements. The floor was then open for discussion allowing the instructor and fellow students an opportunity to further critique or comment on desired design features or potential changes to the product.

\section{REFLECTION}

The educational benefits of the design critiques were two-fold by both encouraging student engagement while promoting design thinking. First, the active learning aspect fostered student engagement within the virtual environment. Student participation is fostered only when students find value coupled with the expectation they can succeed at the task. ${ }^{2}$ Value in the assignment was inherent in the students' ability to critique designs of interest in their life or that of a peer. Success on the project was encouraged through the standardized format providing a template for student success. Student interest was evident in the classroom discussion through students commenting on the designs chosen by their peers, often making additional suggestions for design improvements. In instances where discussion lagged questions requiring student reflection were posed to initiate conversation such as, "Does anyone else have experience using this product?", "Is this device easier to use than other designs on the market?" or "Are there any features of this design that we've encountered in other devices?"

Academically, the activity encouraged students to recognize efficacy in the way products/processes are designed for humans. Analysis and evaluation of realword design applications provided a means for students to apply basic biomechanics knowledge through higher order thinking methods essential for advanced learning. ${ }^{10}$ The repetitive nature of the design critiques fostered student ability to identify and appreciate everyday designs through a critical lens. Positive student feedback indicated a connection was made between the course material and outside experiences. One student commented in the course evaluation, "I enjoyed the design critiques, they demonstrated how much I had learned in this class." Another stated, "This was a fun way to relate what we were learning in class to what we actually experience day-to-day. It was also fun because it seemed many people had mutual experiences with the same bad designs."

While a benefit of the assignment as implemented was to foster conversation in the synchronous classroom, the assignment could be accomplished online in several formats to meet Universal Design for Learning principles. $^{7}$ A scaffolding approach may be implemented in which the students begin with a critique 


\section{A Design Critique \#1: Design for Anthropometry Due: 4/8}

Purpose: To encourage students to notice, critique and challenging real-world designs thereby developing an aptitude for design thinking.

Task: You are to critique a design you have encountered at home, school, work or your community. Critique the design on the provided PowerPoint template. Upload the template to Blackboard by midnight, 4/8. You will be asked to provide a 1-2 min design critique related to your chosen design in the virtual classroom on $4 / 9$.

*I understand due to COVID-19 your activity outside of the home is restricted. Instead of searching the community for designs you could also consider exceptional/questionable designs you've previously encountered at work, in a hobby or around your house. If you're unable to provide a picture you took of the device, object or process feel free to source the internet for a comparable design.

B Design Critique $1 \quad$ Topic:

\section{Device/Object Name}

$\square$ Exemplary $\square$ Questionable

What I like/dislike about this design:

I would improve this design by... Here

FIGURE 1. (a) Instructions and (b) template provided to students in preparation for synchronous, online design critiques.

reviewed only by the instructor, followed by assignments in discussion boards with peer feedback via comments, and finally presentations in the synchronous group discussions. Flexibility could be achieved by allowing students to choose to pre-record over a short PowerPoint presentation and then share with the class for either an online or live discussion. Pre-recordings would also allow equitable participa- tion in cases where students may not have reliable access to the online classroom.

During Winter 2020 a basic grading structure was employed where students simply received points for (1) completing the template, and (2) presenting to the class. Though the depth of a critique was not numerically assessed, students were given verbal feedback by 
the instructor during class discussion and through comments in the online grade book. The structure seemed appropriate as many students experienced stress in transitioning online and apprehension toward participation in the virtual environment. However, in future semesters, as students and faculty become more proficient with remote education, a modified specifications grading methodology will be applied to score the online design critique to further encourage more indepth design analysis. The grading scale will be based off of an EMRF rubric where points are earned on a four-point scale (4: Exemplary, 3: Meets Expectations, 2: Revisions Needed, 1: Fragmented). ${ }^{8}$ Specific design comments will continue to be shared with students. Additionally, the online format could eventually be implemented in conjunction with the more in-depth journal entries and graded by the more detailed rubric.

The implementation of an online design critique using a PowerPoint template instead of the design journal method was implemented in response to limited levels of discussion occurring in the online classroom. In prior years, prompting students to reference a design from his or her journal effectively enriched classroom discussion. Additionally, in the face to face classroom students easily shared pictures or drew existing and proposed designs for the class explaining the benefits or drawbacks of each iteration. The PowerPoint template provided a quick way to share designs online and students became more engaged with this format. The quality of design critique was not observed to be significantly different than prior semesters. However, due to COVID19 many more designs seemed to be related to hobbies (for example; woodworking, sports) than examples encountered in internships or on campus. The slight change in content is attributed to the limited mobility during the state's stay-at-home order and a natural tendency to draw upon current experiences and interactions. Overall, the activity fostered the same ability to assess a wide range of designs while cultivating a more robust online classroom discussion.

Online design critiques are an active learning technique encouraging student engagement in the synchronous classroom. The ability for students to evaluate everyday designs led to student "buy in" to the assignment and thereby motivated participation in live discussions. Students connected with one another in the virtual classroom through an activity that matched knowledge gained in the course with designs of interest in their everyday life. The assignment is easily adapted for asynchronous applications outside of a synchronous classroom through discussion boards or pre-recorded lectures and lends itself well to Universal Design for Learning.

\section{FUNDING}

Dr. Conrad is funded through a Clare Boothe Luce Professorship awarded by the Henry Luce Foundation.

\section{CONFLICT OF INTEREST}

The author has no conflicts of interest related to this work.

\section{ETHICAL APPROVAL}

No approval is necessary for this paper.

\section{CONSENT TO PARTICIPATE}

Informed consent not required for this Teaching Tip.

\section{CONSENT FOR PUBLICATION}

The author consents to publication of this work.

\section{AUTHOR CONTRIBUTIONS}

The sole author created the online design critique assignment in response to COVID-19 remote learning and has written the manuscript in its entirety.

\section{REFERENCES}

${ }^{1}$ ABET Engineering Accreditation Commission. 2018-2019 Criteria for Accrediting Engineering Programs. Baltimore: ABET; 2019

${ }^{2}$ Ambrose SA, Bridges MW, DiPietro M, Lovett MC, Norman MK. How Learning Works: Seven ResearchBased Principles for Smart Teaching. New York: Wiley; 2010.

${ }^{3}$ Cavanagh AJ, Aragón OR, Chen X, Couch BA, Durham MF, Bobrownicki A, Hanauer DI, Graham MJ. Student buy-in to active learning in a college science course. CBE Life Sci. Educ. 2016;15(4):ar76.

${ }^{4}$ Dixon, G. Technical design reviews in capstone. Proceedings of the American Society for Engineering Education, Indianapolis, IN. 2014.

${ }^{5}$ Freeman S, Eddy SL, McDonough M, Smith MK, Okoroafor N, Jordt $\mathrm{H}$, Wenderoth MP. Active learning increases student performance in science, engineering, and mathematics. Proc. Natl Acad. Sci. U.S.A. 2014;111(23):8410-5.

${ }^{6}$ Muilenburg LY, Berge ZL. Student barriers to online learning: a factor analytic study. Distance Educ. 2005;26(1):29-48.

${ }^{7}$ Rose D. Universal design for learning. J. Spec. Educ. Technol. 2000;15(3):45-9.

${ }^{8}$ Stutzman RY, Race KHEMRF. Everyday rubric grading. Math. Teach. 2004;97(1):34. 
${ }^{9}$ Waters TR, Putz-Anderson V, Garg A. Applications Manual for the REVISED NIOSH Lifting Equation. Cincinnati, OH: U.S. Dept. of Health and Human Services, Public Health Service, Centers for Disease Control and Prevention, National Institute for Occupational Safety and
Health, Division of Biomedical and Behavioral Science; 1994.

${ }^{10}$ Yen TS, Halili SH. Effective teaching of higher order thinking (HOT) in education. Online J. Distance Educ. eLearn. 2015;3(2):41-7. 